\title{
Viruses and lymphocytes in rheumatoid arthritis. I. Studies on cultured rheumatoid lymphocytes
}

\author{
MARY NORVAL, HELENA HART, AND B. P. MARMION \\ From the Department of Bacteriology, University of Edinburgh Medical School, Edinburgh
}

SUMMARY Synovial fluid lymphocytes from patients with rheumatoid arthritis have been examined for evidence of a productive infection with retroviruses by electron microscopy, labelling with ${ }^{3} \mathrm{H}$-uridine, growth in soft agar, and culturing in conditioned medium. No such viruses were detected. In addition, the synovial lymphocytes were activated before fusion and cocultivation with several cell lines which have proved permissive for primate retroviruses. Monitoring these cultures subsequently by reverse transcriptase assay, labelling with ${ }^{3} \mathrm{H}$-uridine, and membrane immunofluorescence gave no indication that retroviruses were present.

A possible viral aetiology for rheumatoid arthritis (RA) has been much canvassed and investigated during the last 10 years but with negative results so far. Much of the search has concentrated on the fibroblast-like cells cultured from the RA synovial membrane or synovial fluid effusions and thought to be derived from type B or C lining cells (Smith and Hamerman, 1969). However, there is little evidence for viral genomes, productive viral infection, or neoantigens in such cells. For summaries and reviews see Hamerman (1975), Marmion and Mackay (1977), and Marmion (in press).

Less attention has been paid in RA to the possible production of disease as a result of the interaction of virus with cells of the immune and immunoregulatory system (Denman, 1975; Talal, 1977; Marmion and Mackay, 1977; Marmion, in press).

Reports on the relative proportion and classes of lymphocytes in rheumatoid synovial fluid and peripheral blood vary. Several investigations record an increase in T-cell numbers, a decrease in B-cell numbers (Froland et al., 1973; Holborow et al., 1975), and the presence of a population of null cells, up to $32 \%$ (Winchester et al., 1974). Others have found an increase in B-cells (Mellbye et al., 1972). The lymphocytes in RA synovial membranes, as distinct from the synovial fluid, are predominantly T-cells (Loewi, 1975).

There may be a marked diminution in responsiveness of synovial lymphocytes of RA patients to

Accepted for publication 19 December 1978.

Correspondence to Dr Mary Norval, Department of Bacteriology, University of Edinburgh Medical School, Teviot Place, Edinburgh EH8 9AG. various mitogens, especially PHA (Stratton and Peter, 1972; Panayi, 1973; Holborow et al., 1975) but reports are not consistent. Also the reactivity of peripheral blood lymphocytes in mixed lumphocyte culture may be depressed (Astorga and Williams, 1969). It is possible that the cells may already be activated or that the receptor sites for the antigen may be blocked; such effects might be virally induced.

In view of these pointers to disordered lymphocyte function in RA we decided to investigate RA synovial and peripheral blood lymphocytes for evidence of viral infection or of viral gene products. We were particularly interested in the association of retroviruses (type $\mathrm{C}$ or oncoviruses) with lymphocytes. This interaction has been well studied in various mice strains in which the immune response to endogenous viruses is modified by genetic factors involved with infectivity and expression (review, Ihle and Hanna, 1977). In human beings there have been extensive attempts to detect retroviruses, especially in association with leukaemia or lymphoma. Several isolations have been made, one of which was from cultured myeloid leukaemia cells. This virus was closely related to simian sarcoma virus and baboon endogenous virus (Reitz et al., 1976), and it can be established as a chronic infection in various cell lines (Teich et al., 1975).

A range of different cell-virus relationships exists with retroviruses and extends from productive infection to an integrated 'silent' genome. In addition some viruses are unable to replicate in cells of the same species from which they have been derived (xenotropic viruses). During the course of this study we used methods described by other workers for 
successful culture of several xenotropic viruses. These involved fusing or cocultivating the lymphocytes with potentially permissive cells from another species. For example, baboon endogenous viruses have been isolated from normal baboon tissue by cocultivation with various permissive cell lines from rhesus monkey lung and dog thymus (Todaro et al., 1974). In addition cultivation of integrated and silent retroviruses may require an activating step often involving turnover of cellular DNA or modification of DNA synthesis. One method of accomplishing this with lymphocytes is by a mixed lymphocyte reaction as demonstrated in mice (Hirsch et al., 1972; Sherr et al., 1974).

In the present investigation we first of all examined the synovial lymphocytes for any evidence of a productive infection with retroviruses by electron microscopy, scanning electron microscopy, labelling with ${ }^{3} \mathrm{H}$-uridine, and culturing in conditioned medium, which has proved successful for sustained growth of human myelogenous leukaemia cells (Gallagher and Gallo, 1975). In addition methods were used to activate the lymphocytes before fusion and cocultivation with various cell lines which have proved permissive for primate retroviruses. The cells were subsequently examined for virus by labelling with ${ }^{3} \mathrm{H}$-uridine, the culture supernatant being assayed for reverse transcriptase activity, and finally for the presence of virus-coded proteins in the cell membranes by immunofluorescence. In the accompanying paper the results of testing lymphocytes for the presence of viral antigens on their membranes, including retrovirus antigens by immunofluorescence and radioimmunoassay, are described (Hart et al., 1979).

\section{Materials and methods}

SEPARATION OF LYMPHOCYTES

Specimens of paired synovial fluid and peripheral blood were obtained from patients attending the Northern General Hospital and were used within 2 hours of removal. Early in this study they were heparinised immediately $(10 \mathrm{U} / \mathrm{ml})$, but later the synovial fluid was left untreated while the peripheral blood was defibrinated with glass beads. Synovial fluids were treated with $80 \mathrm{U} / \mathrm{ml}$ hyaluronidase at $37^{\circ} \mathrm{C}$ for 30 minutes. Both were then separated on Triosil-Ficoll gradients (24 parts $9 \%$ Ficoll mixed with 10 parts $34 \%$ Triosil; centrifugation at 2000 r.p.m. for $20 \mathrm{~min}$.). The lymphocyte-rich fraction was washed twice in Hanks's salt solution and counted after staining by the trypan-blue exclusion method or a special Boullard haematoxylin stain.

LYMPHOCYTE CULTURE

(a) The lymphocytes, generally at a concentration of around $10^{6} / \mathrm{ml}$, were routinely cultured in Earlesbased Eagles complete medium (EE medium) containing $100 \mu \mathrm{g} / \mathrm{ml}$ streptomycin and $100 \mathrm{IU} / \mathrm{ml}=$ penicillin supplemented with $20 \%$ autologous human $\stackrel{S}{\stackrel{9}{9}}$ serum. They were incubated at $37^{\circ} \mathrm{C}$ in $5 \% \mathrm{CO}_{2}$. 웅

(b) ${ }^{3} \mathrm{H}$-uridine labelling. The lymphocytes (from 흠 $2 \times 10^{6}$ up to $10^{7}$ ) at a concentration of $10^{6} / \mathrm{ml} \stackrel{5}{\overrightarrow{7}}$ were incubated overnight in EE medium containing $\triangle$ $20 \%$ fetal calf serum or autologous serum or homo- $\$$ logous plasma, plus $\left(5-^{3} \mathrm{H}\right)-$ uridine $(20 \mu \mathrm{Ci} / \mathrm{ml}) \vec{\circ}$ Amersham). Culture supernatants were concentrated using $\left(\mathrm{NH}_{4}\right)_{2} \mathrm{SO}_{4}$ (Grayzel, 1973), and were fraction- $\vec{\omega}$ ated on sucrose gradients by the method outlined in Norval and Marmion (1976). In addition some lymphocytes were cultured for 4 days in the presence $\omega$ of phytohaemagglutinin $(50 \mu \mathrm{g} / \mathrm{ml})$ before the label $\sigma$ was added.

(c) Cocultivation with fetal skin fibroblasts. Approximately equal numbers of lymphocytes were 을 added to monolayers of human fetal skin fibro- blasts cultured in EE medium plus $10 \%$ fetal calf serum. The medium was changed weekly and the $\mathbb{\Phi}$ cultures split fortnightly.

(d) Use of conditioned medium. The lymphocytes $\mathbb{\Phi}$ were cultured in conditioned medium from fetal $\vec{\theta}$ skin fibroblasts; i.e., EE medium plus $10 \%$ fetal calf serum which had been in contact with the cels for about 4 days and which had been spun deposit any cells.

(e) Colony formation in soft agar. $8 \times 10^{4} / \mathrm{ml}$ lymphocytes were mixed with complete 199 medium containing a final concentration of $0.3 \%$ agar and $20 \%$ human serum. In addition the lymphocytes were $\overline{\bar{o}}$ grown on prepared feeder layers. These comprised 3 dextran separated mononuclear blood cells $\left(10^{6} / \mathrm{ml}\right)$ in complete 199 medium containing $0.5 \%$ agar and $20 \%$ human serum, and irradiated at $100 \mathrm{rad} / \mathrm{min}$ for 10 min (Goldman et al., 1974; Prival et al., 1974).

ELECTRON MICROSCOPY

Packed lymphocytes were prepared for electron microscopy after incubation overnight. The blocks were sectioned on a LBK Ultratome 11 and the sections viewed on a Hitachi HU11A electron $\rightarrow$ microscope.

\section{SCANNING ELECTRON MICROSCOPY}

Lymphocytes after separation on Triosil-Ficoll $N$ gradients were washed in serum-free medium and prepared for scanning electron microscopy using the 0 method of Alexander et al. (1976). The specimens were examined in a Cambridge stereoscan 180 microscope at $30 \mathrm{kV}$ and $45^{\circ}$ tilt.

POLYMERASE ACTIVITY
The synovial lymphocytes were assayed as described by Norval et al. (1975). 
FUSION AND CO-CULTIVATION

(a) Stimulation of lymphocytes. Separated synovial fluid lymphocytes were stimulated in a mixed lymphocyte reaction (MLR). The preparation of lymphocyte pools, as stimulators of MLR, and the test have been described in detail by Urbaniak et al. (1978). Synovial fluid lymphocytes and stimulators were mixed in a $1: 3$ ratio. $0.5 \mu \mathrm{Ci}\left({ }^{3} \mathrm{H}\right.$-methyl) thymidine (Amersham) was added to a test sample in a microtitre well after 3 days' incubation for 18 hours. Only those synovial fluid lymphocytes which showed positive MLR were used in the subsequent fusion. The remainder of the lymphocytes was stored in liquid nitrogen during the MLR test and used directly in the fusion.

(b) Polyethylene glycol (PEG) fusion and cocultivation. Method as described by Pontecorvo (1975) with the modification that the PEG was drained off the cell sheet immediately. One batch of PEG (6000-7500 mol. wt., BDH), checked for toxicity to cultured cells, was used throughout. Three sets of lymphocytes were prepared: (i) $10^{6}$ synovial fluid lymphocytes containing $3 \times 10^{6}$ stimulators, (ii) $10^{6}$ synovial fluid lymphocytes, (iii) $3 \times 10^{6}$ stimulators.

(c) Sets from 7 patients with RA were used, and these were fused with $10^{5}$ cells of the following cell lines known to support the growth of simian sarcoma virus and the baboon endogenous virus, which had been kindly provided by Dr N.Teich:A204 (human rhabdosarcoma), 7605L (human lung fibroblast), CCL64 (mink lung fibroblast) for 2 cultures; Tb-1-Lu (bat lung epithelial), CCL64 (mink lung fibroblast), D17 (dog fibrosarcoma) for 5 cultures. The medium used was EE plus 2, 5 , or $10 \%$ fetal calf serum and culture was continued for a period of 8 weeks with the medium being changed twice weekly and the cells being split every fortnight. In one case the synovial fluid lymphocytes were pretreated for 24 hours with $40 \mu \mathrm{g} / \mathrm{ml}$ IUDR plus $10^{-6} \mathrm{M}$ diethylstilbestrol or IUDR plus $10^{-6} \mathrm{M}$ hydrocortisone before fusion. After fusion culturing was continued in the presence of the appropriate hormone (Wu et al., 1976). At various times the cultures were examined for evidence of retrovirus induction by:

(i) Assaying the reverse transcriptase activity of the culture supernatant at 3 and 7 weeks by the method of Dr N. Teich (personal communication).

(ii) Labelling with ${ }^{3} \mathrm{H}$-uridine at 7 weeks followed by concentration of the culture supernatant and sucrose density gradient centrifugation as outlined by Norval and Marmion (1976).

(iii) XC test at 5 weeks (for 2 cultures only) by the method of Rowe et al. (1970).

(iv) Immunofluorescence at 7 weeks with various antiretrovirus antisera. Goat antisera to RD-114 (Tween-ether disrupted) and SSAV (Tween-ether disrupted) were originally obtained from $\mathrm{Dr} \mathrm{J}$. Gruber (National Cancer Institute), and used at $1 / 10$ dilution in PBS, supplemented with $2 \%$ fetal calf serum (PBS-FCS). Rabbit antisera were later prepared to RD-114 and SSAV antigens (Hart et al., 1979) and used at a dilution of $1 / 20$ in indirect immunofluorescence tests on acetone-fixed cells grown on cover-slips (Schmidt et al., 1966; Lennette et al., 1967). Horse anti-human lymphocyte serum was kindly donated by Dr K. James. This serum was absorbed with acetone dried mink liver powder to give a working dilution of $1 / 4$. Sheep anti-rabbit immunoglobulin and rabbit anti-horse immunoglobulin, both conjugated with fluorescein isothiocyanate (Wellcome Reagents), were used diluted to $1 / 8-1 / 16$ in PBS-FCS. Rabbit anti-goat IgG FITC (Nordic Diagnostics Ltd.) was used at 1/8 dilution in PBS-FCS.

\section{Results}

\section{ELECTRON MICROSCOPY}

Five preparations of paired synovial fluid and peripheral blood lymphocyte from rheumatoid arthritis patients and 2 pairs from osteoarthrosis patients were examined after ultrathin sectioning. The lymphocytes from all sources looked normal, with large indented nuclei, compact chromatin, and a group of mitochondria opposite the indentation and a few mitochondria and ribosomes in the remaining cytoplasm. No membrane maturing or other virallike structures were found. It was impossible to distinguish whether the lymphocytes were from the synovial fluid or the peripheral blood. Other cells seen included macrophages, monocytes, and a large number of platelets, particularly in the synovial fluids.

Four pairs of synovial fluid and peripheral blood lymphocytes from RA patients, 1 from juvenile RA, and $1 \mathrm{OA}$ were examined by scanning electron microscopy. No surface features were found which distinguished cells from the 2 sources. Measurement of size showed that the lymphocytes from peripheral blood seemed to fall into 2 groups, which may correspond to $\mathrm{T}$ and $\mathrm{B}$ cells, while only the smaller size was present in the synovial fluid population. According to Polliack et al. (1973) the B cells in the blood are slightly larger than the $T$ cells, so the smaller group common to both blood and synovial fluid may be $T$ lymphocytes.

CULTURING OF LYMPHOCYTES

Initially synovial fluid lymphocytes and peripheral blood lymphocytes from 10 patients with RA, 1 
with juvenile RA, and 5 non-RA were incubated overnight in medium containing $20 \%$ fetal calf serum or autologous serum or homologous plasma, and $20 \mu \mathrm{Ci} / \mathrm{ml}^{3} \mathrm{H}$-uridine in an attempt to label any RNA-containing virus which might be released into the fluid phase of the culture. Sucrose density gradient analysis of the concentrated fluid phase did not reveal labelled material at the appropriate density for a retrovirus. Rather more cell lysis occurred in the synovial fluid lymphocyte cultures than in the peripheral blood, particularly when calf serum or autologous human serum was used. This gave rise initially to patterns simulating virus release but the labelled material was sensitive to RNase and the release was less in homologous plasma.

Three cultures of synovial fluid lymphocytes from different patients were incubated first of all in the presence of phytohaemagglutinin for 4 days before adding ${ }^{3} \mathrm{H}$-uridine. Again no peaks of labelled material typical of RNA viruses and retroviruses in particular were found.

As there did not appear to be a productive infection with an RNA virus in the synovial lymphocytes, the cells were examined for their DNA polymerase activity to determine if they contained any RNA-dependent DNA polymerase. Synovial fluid lymphocytes from 2 patients (1 RA and 1 possible juvenile RA) were assayed for polymerase activity and compared to a rheumatoid lymphoblastoid cell line kindly provided by Dr Ford (see below). The activity in all cases was found to be typical of that described in stimulated lymphocytes, that is an RNA-primed DNA-directed polymerase, not viral reverse transcriptase (Bobrow et al., 1972). There was little stimulation by poly(rA). $\mathrm{dT}_{10}$, and almost complete inhibition by actinomycin $\mathrm{D}$.

It was noticed that if the cultures were kept for a longer period than overnight the lymphocytes gradually began to die, and after a month few viable cells remained. Human serum seemed to prolong the viability when compared to fetal calf serum, but this was only marginal. In order to examine the cells properly and to increase the numbers of synovial lymphocytes from any one patient, we tried various methods which have been successful in other systems. For example, conditioned medium from whole human embryo cells has been used to sustain growth of human myelogenous leukaemia cells in suspension culture (Gallagher and Gallo, 1975). Therefore the synovial fluid lymphocytes from 4 RA patients were cultured in conditioned medium prepared from fetal skin fibroblasts. The survival of viable cells was higher in this medium than in EE medium with $10 \%$ fetal calf serum over the first month, but subsequently they began to die and none survived longer than 2 months. Again, when synovial fluid lymphocytes from 4 RA patients were cocultivated with fetal skin fibroblasts, they survived as viable cells throughout 2 months $\stackrel{5}{\rightarrow}$ but were not dividing. The culture supernatant was tested at 4 and 8 weeks for reverse transcriptase activity and was negative in all cases.

Ford and Smiley (1973) reported the spontaneous occurrence of a continuous line of lymphoblastoid cells which appeared during culture of an RA synovial membrane. These cells contain EBV genome and synthesise IgG of the specificity of rheumatoid factor in culture. However, attempts to transform synovial fluid lymphocytes from 4 RA patients with EBV by the method of Miller et al. (1974), known to be successful with cord blood lymphocytes, were failures.

GROWTH OF LYMPHOCYTES IN SOFT AGAR

Lymphocytes from 3 RA synovial fluid specimens stored in liquid nitrogen and 3 normal peripheral blood lymphocytes were cultured in soft agar with and without a feeder layer of peripheral blood mononuclear cells inactivated with $x$-rays. All plates were viewed after 10 days. A few cells pro liferated in plates without feeder layers (Table 1) but by day 12 these were no longer detected. Sub stantially more clusters were seen on the plates with feeder layers but never any colonies. ('Clusters' were considered to contain 10-20 cells and 'colonies' more than 50). Also there were no differences in the numbers of clusters formed between normal peripheral blood and rheumatoid synovial fluid lymphocytes. Clusters from one synovial fluid lymphocyte culture (number 2 in Table 1) were fixed for electron microscopic examination. The cell type could not be identified from the cellular debris, but no viral particles were seen in this dividing population of cells.

Table 1 Numbers of 'clusters' of cells seen on day 10 after culturing lymphocytes in soft agar with and without a feeder layer of peripheral blood mononuclear cells irradiated at $100 \mathrm{rad} / \mathrm{min}$ for $10 \mathrm{~min}$

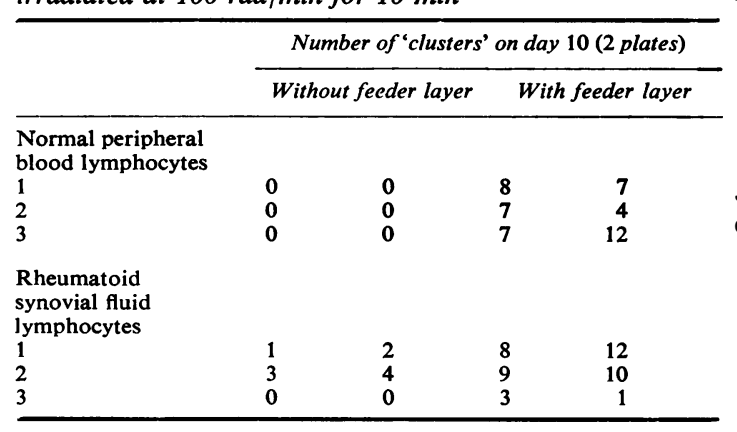




\section{PEG FUSION}

As no proliferation or long-term culture of synovial lymphocytes was obtained using the above methods, it was decided to try activating the lymphocytes and then to fuse them with cell lines which had proved permissive for a variety of primate retroviruses. Only those cells able to be activated by a MLR were used for the subsequent fusion and cocultivation.

In the first place the efficiency of fusion when PEG was used was determined by forming heterokaryons of synovial lymphocytes and CCL64 mink cells. Two days after PEG treatment the cells were stained by immunofluorescence by means of anti-human lymphocytic serum.

Heterokaryons were frequent and were mainly binuclear, with numerous long appendages which were not detectable in mononuclear cells (Fig. 1). The heterokaryons were not present at the end of the 7-week culture.

After activation the synovial fluid lymphocytes were fused with 3 out of a selection of 5 cell lines, A204, 7605L, CCL64, Tb-1-Lu, and D-17, and the cultures carried for an 8-week period with periodic testing for evidence of retrovirus expression. In 1 instance the lymphocytes were pretreated with IUDR and either diethylstilbestrol or hydrocortisone before fusion. In all, synovial fluid lymphocytes from 7 patients were used. These patients had RA for periods ranging from 1 year to 27 years, and varied from seronegative to seropositive.

The cultures were followed using several methods. Firstly, the supernatant was assayed for reverse transcriptase activity, and in all cases this was negative, indicating that the cells were not producing retroviruses. A positive control of culture supernatant from RD cells infected with RD-114 virus was always included in the samples to be assayed. In addition labelling with ${ }^{3} \mathrm{H}$-uridine followed by sucrose density gradient centrifugation did not show any peak at the density of a retrovirus, i.e., $1 \cdot 16$ $1.18 \mathrm{~g} / \mathrm{cm}^{3}$, again indicating that there was no productive virus infection. In some cases an XC test was carried out. This has been used to detect murine leukaemia virus genome in cells as these will form plaques when placed in contact with XC cells (rat tumour cells transformed by Rous sarcoma virus) (Rowe et al., 1970). Plaques and syncytia were never formed when the fused cells were cultured in the presence of XC cells. The method was checked by using mouse 3T3 cells infected with AKR type of murine leukaemia virus.

The final test involved immunofluorescence on acetone-fixed cells grown on coverslips which should detect retrovirus membrane antigens, if these are being expressed in the fused cells. Antisera to the viruses RD-114 and SSAV were chosen. The first is an endogenous cat virus with a close antigenic relationship to the baboon endogenous virus, and the second is a simian sarcoma virus. Both share various antigenic determinants, such as p30 and gp69-71, with other mammalian species and should therefore be able to detect any retroviral antigens in human cells. Originally goat antisera to the 2 viruses, which had been Tween-ether disrupted, were used, but later antisera prepared in rabbits were used (Hart et al., 1979). In no case was there any suggestion of positive immunofluorescence.

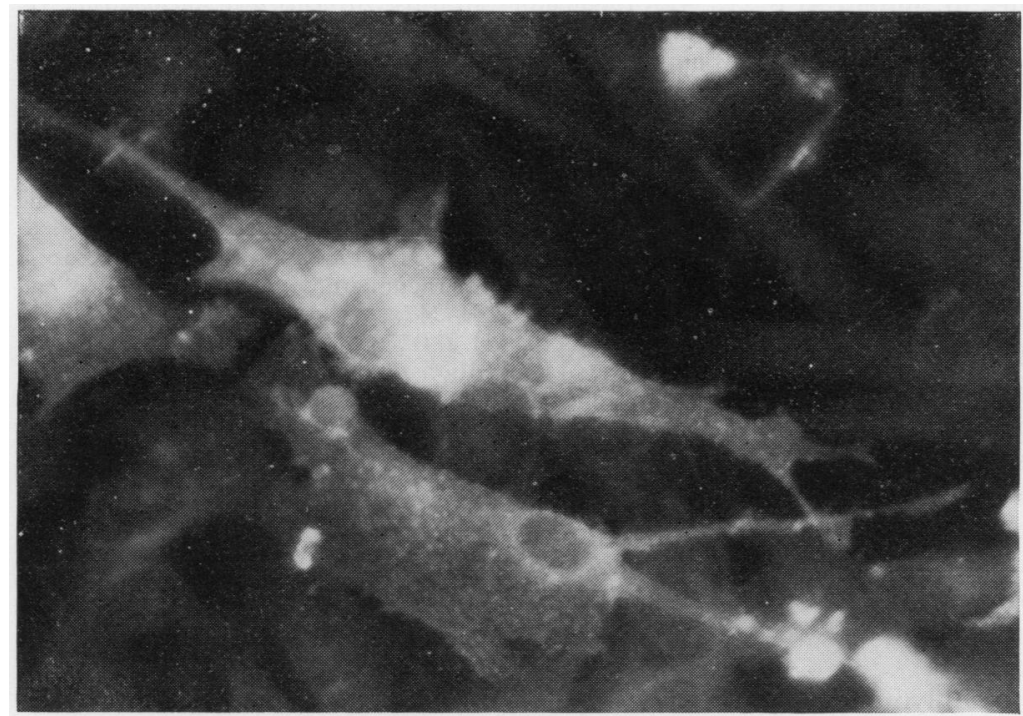

Fig. 1 Heterokaryons formed by PEG fusion of synovial lymphocytes with CCL 64 cells, stained with horse anti-human lymphocyte serum and anti-horse FITC conjugate to demonstrate a human nucleus within a mink lung fibroblast and human antigens on the cell surface. 


\section{Discussion}

In the past few years much attention in RA research has focused on the type B synovial lining cell and its presumed derivative in culture, the synovial fibroblast. Although these cells have some abnormal characteristics when compared to fibroblasts from other disease conditions such as osteoarthrosis, there is no evidence of neoantigens on the cell surface, either virally induced or arising from mutation.

In this paper we have attempted to look at the lymphocytes present in the synovial fluid effusions of patients with RA to see if they contain RNA viral genes that might be linked with the chronic inflammatory state of the joint.

It seemed unlikely, especially in the light of the thorough attempts by various groups of workers to isolate retrovirus from human leukaemia cells, that the synovial lymphocytes would be productively infected with a virus, and, indeed, our morphological results after ultrathin sectioning did not indicate any abnormalities in these cells compared to those from the peripheral blood, and there was no evidence of virion production. Similarly the surface of the lymphocytes did not differ from the 2 sources when examined by scanning electron microscopy. Labelling with ${ }^{3} \mathrm{H}$-uridine also did not indicate a productive viral infection.

We turned then to more indirect methods of detecting viral information in RA lymphocytes. It is of interest in this context that a retrovirus, SP104, has been associated with canine systemic lupus erythematosus (SLE), and by immunofluorescence viral membrane antigens have been demonstrated on some peripheral blood lymphocytes in human SLE (Schwartz, 1975). In addition, an antigen, p30, related to mammalian type $\mathrm{C}$ viral protein has been localised in renal glomeruli in human SLE (Mellors and Mellors, 1976). More recently, however, viral mRNA of SP104 was not detected in either human or canine SLE tissues by sensitive methods of nucleic acid hybridisation (Quimby et al., 1978), a result which is hard to reconcile with the previous data. In the accompanying paper Hart et al. (1979) describe experiments to detect retrovirus antigens on the membranes of synovial lymphocytes by radioimmunoassay and immunofluorescence with uniformly negative results. However, possibly it was necessary to culture the cells to induce the virus, and indeed, as in the case of xenotropic viruses, which will replicate only in cells of a different species, it might have been necessary to use methods of induction, fusion with permissive cells, and cocultivation before virus is isolated.

Our attempts to culture the synovial lymphocytes were not successful, using different species of serum, conditioned medium, cocultivation with fibroblasts, $\frac{}{\omega}$

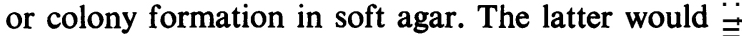
have indicated transformation of a lymphocytic $\stackrel{\vec{s}}{\rightarrow}$ population. Finally, then, the lymphocytes were $\bar{C}$ stimulated by an MLR and fused using PEG with a variety of cell lines known to be permissive for $\frac{\bar{s}}{7}$ several primate retroviruses. Heterokaryons were $\mathscr{\complement}$ formed which were monitored over 8 weeks by several methods, ${ }^{3} \mathrm{H}$-uridine incorporation, reverse $\vec{\bullet}$ transcriptase activity of the culture supernatant, $\mathrm{XC} \stackrel{\odot}{\odot}$ test, and immunofluorescence with antisera to $\vec{\omega}$ RD-114 and SSAV, which should detect mammalian interspecies and group antigens. All results were negative.

Thus in this systemic study we have not been able to detect any viral information in RA synovial cr lymphocytes and very few differences in their characteristics compared to peripheral blood lympho- 음 cytes of the same patient.

We wish to thank Mrs Alexia Graham, who did the transmission and scanning electron microscopy reported in this 3 paper, and Miss Sheena Tuach for expert technical assistance. The help of Mrs Leonora Hislop and the staff at the Rheumatic Diseases Unit, Northern General Hospital, $8 \overrightarrow{0}$ providing clinical specimens is gratefully acknowledgea. Grant support throughout this work was given by the Nuffield Foundation.

\section{References}

Alexander, E., Sanders, S., and Braylan, R. (1976). Purported difference between human T- and B-cell surface morphology $\vec{F}$ is an artefact. Nature, 261, 239-241.

Astorga, G. P., and Williams, R. C. (1969). Altered reactivity in mixed lymphocyte culture of lymphocytes from patients with rheumatoid arthritis. Arthritis and Rheumatism, 12, 547-554.

Bobrow, S. N., Smith, R. G., Reitz, M. S., and Gallo, R. C. (1972). Stimulated normal human lymphocytes contain $a_{-}^{-}$ ribonuclease-sensitive DNA polymerase distinct from viral 3 RNA-directed DNA polymerase. Proceedings of the National Academy of Sciences of the USA, 69, 3228-3232.

Denman, A. M. (1975). The viral theory of connective tissue 3 diseases: a review. Medical Biology, 53, 61-84.

Ford, D. K., and Smiley, J. D. (1973). Continuous culture of a B-immunocyte from rheumatoid synovium. Arthritis and Rheumatism, 16, 341-347.

Froland, S. S., Natvig, J. B., and Husby, G. (1973). Immunological characterization of lymphocytes in synovial fluido from patients with rheumatoid arthritis. Scandinavian $N$ Journal of Immunology, 2, 67-73.

Gallagher, R. E., and Gallo, R. C. (1975). Type C RNA W tumour virus isolated from cultured human myelogenous leukaemia cells. Science, 187, 350-353.

Goldman, J. M., Th'Ng, K. H., and Lowenthal, R. M. (1974). In vitro colony forming cells and colony stimulating factor $\bar{D}$ in chronic granulocytic leukaemia. British Journal of Cancer,? 30, 1-12.

Grayzel, A. I. (1973). Uridine incorporation into the media and RNA of cultured rheumatoid synovial cells. Arthritis and Rheumatism, 16, 419-421. 
Hamerman, D. (1975). Evidence for a viral aetiology of rheumatoid arthritis. In The Immunological Basis of Connective Tissue Disorders, pp. 17-34. Edited by L. G. Silvestri. North Holland: Amsterdam.

Hart, H., McCormick, J. N., and Marmion, B. P. (1979). Viruses and lymphocytes in rheumatoid arthritis. II. Examination of lymphocytes and sera from patients with rheumatoid arthritis for evidence of retrovirus infection. Annals of the Rheumatic Diseases, 38, 000-000.

Hirsch, M. S., Phillips, S. M., Solnick, C., Black, P. H., Schwartz, R. S., and Carpenter, C. B. (1972). Activation of leukemia viruses by graft-versus-host and mixed lymphocyte reactions in vitro. Proceedings of the National Academy of Sciences of the USA, 69, 1069-1072.

Holborow, E. J., Sheldon, P. J., and Papamichail, M. (1975). Studies on synovial fluid lymphocytes in rheumatoid arthritis. Rheumatology, 6, 215-218.

Ihle, J. N., and Hanna, M. G. (1977). Natural immunity to endogenous oncornaviruses in mice. Contemporary Topics in Immunobiology, 6, 169-193.

Lennette, E. H., Woodie, J. D., and Schmidt, N. J. (1967). A modified indirect immunofluorescent staining technique. for the demonstration of rubella antibodies in human sera. Journal of Laboratory and Clinical Medicine, 69, 689-695.

Loewi, G. (1975). Inflammatory arthritis: immunology and inflammation at the cellular level. In Current Topics in Connective Tissue Disease, pp. 48-68. Edited by P. J. Holt. Churchill Livingstone: Edinburgh and London.

Marmion, B. P. (in press). Infection, autoimmunity and rheumatoid arthritis. Clinics in Rheumatic Disease.

Marmion, B. P., and Mackay, J. M. (1977). Rheumatoid arthritis and the virus hypothesis. In Bayer-Symposium VI, Experimental Models of Chronic Inflammatory Diseases, pp. 188-211. Springer-Verlag.

Mellbye; O. J., Messner, R. P., De Bord, J. R., and Williams, R. C. (1972). Immunoglobulin and receptors for C3 on lymphocytes from patients with rheumatoid arthritis. Arthritis and Rheumatism, 15, 371-380.

Mellors, R. C., and Mellors, J. W. (1976). Antigen related to mammalian type-C RNA viral p30 proteins is located in renal glomeruli in human systemic lupus erythematosus. Proceedings of the National Academy of Sciences of the USA, 73, 233-237.

Miller, G., Robinson, J., and Heston, L. (1974). Immortalizing and non-immortalizing laboratory strains of EpsteinBarr virus. Cold Spring Habor Symposium on Quantitative Biology, 39, 773-781.

Norval, M., and Marmion, B. P. (1976). Attempts to identify viruses in rheumatoid synovial cells. Annals of the Rheumatic Diseases, 35, 106-113.

Norval, M., Ogilvie, M., and Marmion, B. P. (1975). DNA polymerase activity in rheumatoid synovial membranes. Annals of the Rheumatic Diseases, 34, 205-212.

Panayi, G. S. (1973). Response of rheumatoid synovial fluid lymphocytes to non-specific mitogens. Lancet, 2, 512-513.

Polliack, A., Lampen, N., Clarkson, B. D., de Harven, E., Bentwich, Z., Siegal, F. P., and Kunkel, H. G. (1973). Identification of human $\mathrm{B}$ and $\mathrm{T}$ lymphocytes by scanning electron microscopy. Journal of Experimental Medicine, 138, 607-624.

Pontecorvo, G. (1975). Production of mammalian somaticcell hybrids by means of polyethylene glycol treatment. Somatic Cell Genetics, 4, 379-400.
Prival, J. T., Paran, M., Gallo, R. C., and Wu, A. M. (1974). Colony-stimulating factors in cultures of human peripheral blood cells. Journal of the National Cancer Institute, 53, 1583-1588.

Quimby, F. W., Gebert, R., Datta, S., Andre-Schwartz, J., Tannenberg, W. J., Lewis, R. M., Weinstein, I. B., and Schwartz, R. S. (1978). Characterization of a retrovirus that cross-reacts serologically with canine and human systemic lupus erythematosus (SLE). Clinical Immunology and Immunopathology, 9, 194-210.

Reitz, M. S., Miller, N. R., Wong-Staal, F., Gallagher, R. E., Gallo, R. C., and Gillespie, D. H. (1976). Primate type-C virus nucleic acid sequences (woolly monkey and baboon types) in tissues from a patient with acute myelogenous leukemia and in viruses isolated from cultured cells of the same patient. Proceedings of the National Academy of Sciences of the USA, 73, 2113-2117.

Rowe, W. P., Pugh, W. E., and Hartley, J. W. (1970). Plaque assay techniques for murine leukaemia virus. Virology, 42, 1136-1139.

Schmidt, N. J., Lennette, E. H., Woodie, J. D., and Ho, H. H. (1966). Identification of rubella virus isolates by immunofluorescent staining, and a comparison of the sensitivity of three cell culture systems for recovery of virus. Journal of Laboratory and Clinical Medicine, 68, 502-509.

Schwartz, R. S. (1975). Viruses and systemic lupus erythematosus. New England Journal of Medicine, 293, 132-136.

Sherr, C. J., Lieber, M. M., and Todaro, G. J. (1974). Mixed splenocyte cultures and graft versus host reaction selectively induce an 'S-tropic' murine type C virus. Cell, 1, 55-58.

Smith, C., and Hamerman, D. (1969). Significance of persistent differences between normal and rheumatoid synovial membrane cells in culture. Arthritis and Rheumatism, 12, 639-645.

Stratton, J. A., and Peter, J. B. (1972). Response of synovial fluid and peripheral blood lymphocytes to in vitro stimulation. Arthritis and Rheumatism, 15, 457.

Talal, N. (1977). Autoimmunity and lymphoid malignancy: manifestations of immunoregulatory disequilibrium. In Autoimmunity-Genetic, Immunologic, Virologic and Clinical aspects, pp. 183-206. Edited by N. Talal. Academic Press: London.

Teich, N. M., Weiss, R. A., Salahuddin, S. Z., Gallagher, R. E., Gillespie, D. H., and Gallo, R. C. (1975). Infective transmission and characterization of a C-type virus released by cultured human myeloid leukaemia cells. Nature, 256, 551-555.

Todaro, G. J., Sherr, C. J., Benveniste, R. E., Lieber, M. M., and Melnick, J. L. (1974). Type C viruses of baboons: isolation from normal cell culture. Cell, 2, 55-61.

Urbaniak, S. J., White, A. G., Barclay, G. R., Wood, S, M., and Kay, A. B. (1978). Tests of immune function. In Handbook of Experimental Immunology, 3rd edn., pp. 47.1-47.31. Edited by D. M. Weir. Blackwell: Oxford.

Winchester, R. J., Winfield, J. B., Siegal, F., Wernet, P., Bentwich, Z., and Kunkel, H. G. (1974). Analysis of lymphocytes from patients with rheumatoid arthritis and systemic lupus erythematosus. Journal of Clinical Investigation, 54, 1082-1092.

Wu, A. M., Richardson, L. S., Paran, M., and Gallo, R. C. (1976). A survey on the effect of steroid hormone on type C virus production from cultured murine cells. Cancer Research, 36, 2025-2030. 